\title{
Editorial
}

\section{Dar cuenta y asumir responsabilidades}

El concepto de rendición de cuentas y, por lo tanto, la obligación de asumir responsabilidades y reparar los daños ocasionados por acciones negligentes e irracionales es prácricamente desconocido en El Salvador. Una de las cualidades más valiosas de las democracias, cuando funcionan, es esta obligación de dar cuentas. Cuando los funcionarios no pueden hacerlo o su explicación no es convincente, dimiten de manera automática. Este no es el caso de El Salvador, pese a que se dice ser una democracia. Mientras no haya rendición de cuentas, no podrá haber administración de justicia y El Salvador seguirá presa de la injusticia. De esto trata el siguiente editorial. La manifestación más clamorosa de esta realidad de injusticia en la que vive El Salvador en la actualidad es la existencia de hechos, algunos de ellos horrendos, sin responsables. Los funcionarios estatales tienen que recurrir, entonces, a explicaciones increíbles o a justificaciones inaceptables cuando intentan dar cuenta de esta paradoja.

La trascendencia del caso de los jesuitas está relacionada con este aspecto fundamental en la democracia occidental, pero del cual carece El Salvador. Prueba de ello es que el patrón seguido en este caso se encuentra también en otros crímenes comunes, cuyos hechores gozan de la misma impunidad que los autores intelectuales de la masacre de noviembre de la UCA. No existe, pues, la ruptura en la cual algunos fundamentan su posición de olvidar el pasado.

El editorial reflexiona sobre esta relación al hilo de nueve afirmaciones o tesis, las cuales deben mucho a Margaret Popkin (Peace Without Justice. Obstacles to Building the Rule of Law in El Salvador. Pennsylvania, 2000). 
Tesis 1. El precio pagado por una transición pacifica es la ley de amnistia, con lo cual se sacrificó el derecho de las victimas a la justicia y se contribuyó a la impunidad.

En las negociaciones para poner fin a un conflicto armado es común, y El Salvador no ha sido la excepción, que los responsables de las atrocidades, antes de entregar las armas y el poder y firmar los acuerdos de paz, consigan el compromiso de decretar una amnistía general. En el caso salvadoreño hubo dos amnistías. La primera, cuyo propósito era permitir la integración de la guerrilla del FMLN en el régimen civil y polírico, fue esencialmente de carácter político; pero la segunda, además de poseer este carácter, propio de esta clase de leyes, se extralimitó al incluir una dimensión que le pertenece formalmente a la justicia criminal, tanto que amnistió a funcionarios públicos que no podían beneficiarse de esta gracia, de acuerdo a lo establecido en la Constitución salvadoreña. Los interesados en obtener este beneficio pidieron una amnistía a cambio de renunciar a la guerra y permitir una transición pacífica. Aun cuando lo hubiera querido, lo cual es cuestionable, el gobierno de Cristiani no tenía poder real sobre la Fuerza Armada y los paramilitares como para recortar el alcance de la amnistía solicitada; aunque estaba comprometido a no entorpecer el proceso judicial en los casos investigados por la Comisión de la Verdad y en los cuales hubiera mérito para ello. El Salvador no tenía capacidad para pedir cuentas a quienes violaron los derechos humanos durante la guerra, porque, como se dirá más abajo, tampoco podía pedir responsabilidades al FMLN.

Los interesados en una amnistía amplia y general utilizaron un argumento que, a lo largo de la transición, adquirió carta de ciudadanía, aun cuando no tiene fundamento racional ni ético. Los responsables de atrocidades convencieron a los negociadores de que el futuro de la transición y del nuevo régimen dependía de la amnistía; de lo contrario, habría inestabilidad. Planteada en estos términos, se trataba de una amenaza, y al aceptarla, el Estado salvadoreño quedó convertido en rehén de los amnistiados. Por eso, esta amenaza se repite cada vez que la amnistía es cuestionada. La amenaza ha resultado así eficaz para detener cualquier intento de acusación criminal. Los estados débiles y sin una tradición democrática fuerte son una presa fácil del chantaje de los militares en las transiciones de posguerra. Sin embargo, esto no ocurre siempre así. Todo depende de las condiciones en las cuales es negociada la transición. En Argentina fue posible pedir cuenta a los militares porque, además de estar desacreditados por la ineptitud con la cual dirigieron la política económica, habían sido derrotados en Las Malvinas. Pero no fue posible en Chile, donde el ejército retuvo una cuota de poder importante, la cual le permitió mantener cierto control sobre la transición. En El Salvador, en cambio, el gobierno que dirigió la transición es el mismo que negoció la finalización del conflicto armado, aparte que no estaba comprometido con la búsqueda de la verdad y la justicia. Conscientemente, se opuso a ambas en nombre de la estabilidad y de una falsa paz, fundamentada en 


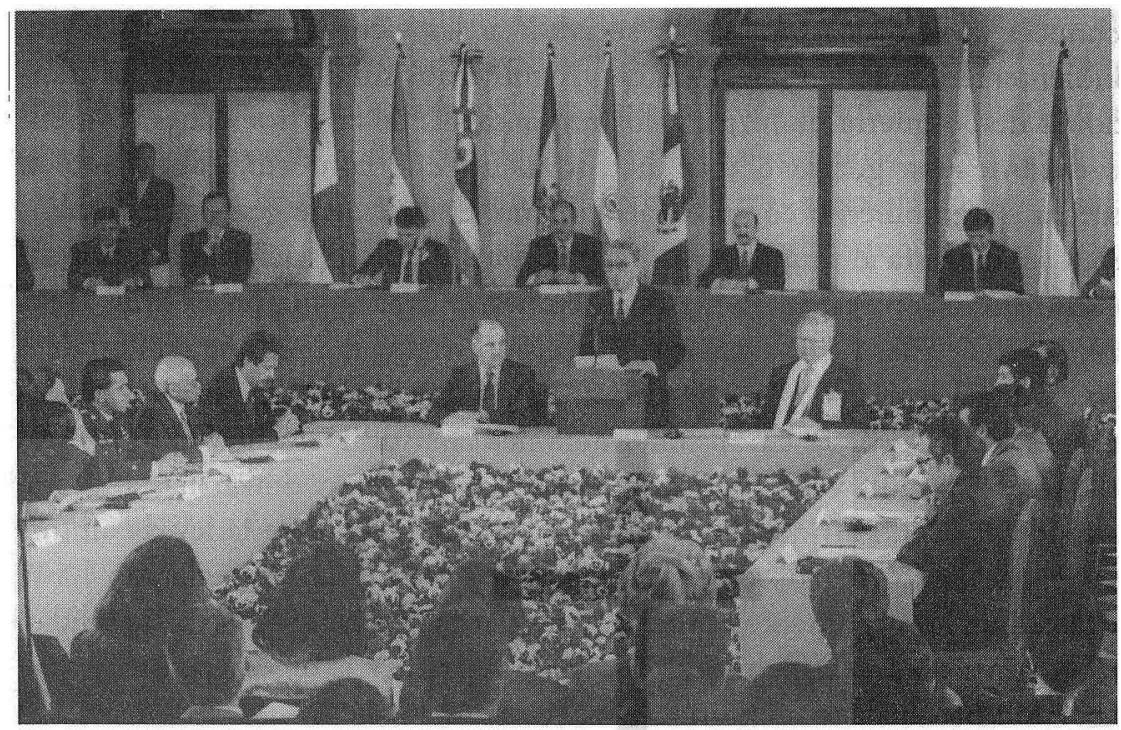

la mentira y el olvido. En estas circunstancias, es imposible que este gobierno acepte reconocer de manera oficial las violaciones de los derechos humanos cometidas por funcionarios públicos, al menos mientras permanezca en el poder. Esta es una poderosa razón por la cual ARENA no puede permitirse perder la próxima elección presidencial.

Mientras tanto, nadie admite haber violado la ley. En la derecha salvadoreña hay algunos incluso que al tratar de justificar su postura lo que hacen, en la práctica, es una apología del crimen. Los dos ex generales salvadoreños llevados a juicio en Estados Unidos, acusados de haber ordenado y encubierto la violación y el asesinato de cuatro religiosas estadounidenses, se vieron forzados a reconocer que tanto el ejército como la Guardia Nacional practicaron la tortura, la desaparición forzada y la ejecución sumaria de manera amplia y sistemática; pero ambos niegan haber tenido poder para detenerlas. Ambos sostienen que las directrices oficiales eran claras, en cuanto a respetar los derechos humanos, pero que no tenían control de sus, subordinados, quienes, en el caso del ex Ministro de Defensa, incluso lo mal informaban. El mismo argumento usó la Fuerza Armada para negar la existencia de órdenes superiores en la masacre de la UCA. En ningún ejército medianamente organizado y mucho menos en uno asesorado muy de cerca por el ejército de Estados Unidos, el cual además pasaba por ser muy profesional y respetuoso de los derechos humanos, ocurre esta clase de hechos sin al menos el consentimiento tácito de los mandos superiores.

Cabe preguntarse entonces si una amnistía fundamentada en estos presupuestos es válida jurídica y éticamente, o lo que es más importante, si debe seguir siendo observada por la sociedad y en particular por los jueces. La comunidad internacional está cada vez más convencida del derecho de la sociedad 
a conocer la verdad acerca de lo sucedido a las víctimas así como, correspondientemente, de la obligación de los gobiernos surgidos durante las transiciones de posguerra de juzgar a los responsables de las atrocidades, cometidas durante una guerra o una dictadura. En este contexto, cabe también recordar a un gobierno como el salvadoreño, el cual tiene grandes expectativas en su apertura al mundo, que los preceptos de la legislación internacional no son discrecionales, es decir, no permiten a cada gobierno decidir si los acata o no, ni a los otros aceptar una decisión nacional contraria a lo establecido en dicha legislación internacional. Esto vale para las repetidas recomendaciones hechas por la Comisión Interamericana de Derechos Humanos al Estado salvadoreño y de las cuales éste ha hecho caso omiso hasta ahora. Tampoco es válido atrincherarse en la constitucionalidad de la ley de amnisría, porque la Corte Suprema de Justicia lo único que ha declarado hasta ahora es que los argumentos utilizados para reclamar su inconstitucionalidad no son consistentes. E incluso ha admitido la existencia de excepciones, cuya aceptación ha quedado a criterio de los jueces.

El gobierno salvadoreño no tiene autoridad moral para solicitar en una cumbre de mandatarios iberoamericanos una condena del terrorismo vasco, cuando protege, o al menos tolera, que terroristas anticastristas utilicen su territorio para sus actividades. El fiasco diplomático experimentado en la cumbre de Panamá demuestra que no se puede ir por el mundo sin tener la propia casa en orden, es decir, ajustada a la legislación internacional, porque, entonces, la política exterior salvadoreña se arriesga a que le echen en cara sus contradicciones. En El Salvador, el terrorismo, y mucho menos el del Estado, nunca ha sido tomado en serio. La aceptación y la sujeción efectiva a la legislación internacional puede que tomen más tiempo del que fuera de desear, pero lo que no se puede poner en duda es la tendencia de la comunidad de naciones, de la cual El Salvador no podrá sustraerse durante mucho tiempo. Si los precepros de la legislación internacional son universales, se puede y se debe pedir cuentas a quienes lo hayan violado.

En algunos casos, y de nuevo El Salvador no es la excepción, algunos de los militares responsables de atrocidades han sido muy útiles en facilitar la transición de la posguerra, tanto en las negociaciones para poner fin al conflicto armado como en el cumplimiento de los compromisos adquiridos en los acuerdos. Sin embargo, esto no debiera llevar a prometer una amnistía general. Es posible negociar un acuerdo y avanzar en la transición sin amnistía. Por eso, los organismos internacionales especializados en la negociación de las transiciones deben tener sumo cuidado y gran claridad para salvaguardar los principios establecidos en el derecho internacional. En concreto, en América no debieran desconocerse la jurisprudencia continental ni los tratados más recientes, por medio de los cuales los estados del continente han adquirido obligaciones específicas en cuanto a investigar y perseguir a los responsables de tortura, desaparición forzada, asesinato y violencia contra la mujer y la infancia. 
No cabe duda que la amnistía es una decisión esencialmente política, pero su alcance no debiera traspasar ciertas restricciones jurídicas. Por lo tanto, no debiera ser una decisión sólo política, sino también jurídica, porque sólo así es posible salvaguardar el derecho de las víctimas a su dignidad, a la justicia y a la reparación. En la última ley de amnistía, los políticos salvadoreños abandonaron a las víctimas a su suerte. Más aún, dadas las circunstancias que rodearon el decreto y el propósito formal de la ley, ésta no es sino la imposición de una minoría sobre la sociedad para protegerse de la acusación criminal. Fue impuesta como el precio a pagar por los acuerdos de paz, aunque ha sido presentada como un bien incuestionable para la sociedad salvadoreña. Los hechos muestran que los más dispuestos a olvidar el pasado son los más deseosos por participar en la política y aquellos que pueden ser acusados de algún crimen. Por eso, ninguno de los partidos políticos, incluido el FMLN, representan de una manera idónea a las víctimas. Todos han atropellado por igual su derecho y el de la sociedad a conocer la verdad y a la justicia, y no contentos con eso, disfrazan sus intereses políticos con la reconciliación y el perdón.

En ningún caso, una ley de amnistía debiera impedir la investigación para conocer la verdad sobre lo acontecido y para identificar a sus responsables. En Sudáfrica, para el caso, los violadores de los derechos humanos podían acogerse al decreto de amnistía sólo después de haber reconocido sus responsabilidades ante un juez. La amenaza de inestabilidad, por lo tanto, debiera poder ser neutralizada con una promesa de indulto, una vez que la verdad y la justicia hayan sido satisfechas. Más aún, los derechos de las víctimas debieran quedar garantizados en cualquier ley de amnistía. En consecuencia, la ley de amnistía salvadoreña viola el derecho internacional, en particular la Convención Americana de Derechos Humanos, porque ha impedido cumplir con las recomendaciones de la Comisión de la Verdad, porque fue aprobada antes de conocer la verdad e identificar a los responsables de las violaciones, porque se aplica a crímenes que el derecho internacional califica como imprescriptibles, porque suprime la posibilidad de exigir responsabilidad civil y porque viola la Constitución salvadoreña al menos en sus artículos 2 y 244. Por todo esto, El Salvador no puede ser considerado un modelo de transición y su desacato al derecho internacional es un desafío abierto, tanto al orden internacional como al orden constitucional propio, que garantiza la vigencia de los tratados internacionales.

la amnistía es una decisión esencialmente política, pero su alcance no debiera traspasar ciertas restricciones jurídicas. Por lo tanto, no debiera ser una decisión sólo política, sino también jurídica, porque sólo así es posible salvaguardar el derecho de las víctimas a su dignidad, a la justicia y a la reparación. 
Tesis 2. Los negociadores nunca discutieron un acuerdo comin para enfrentar lo sucedido durante la guerra. Ninguno de ellos se preocupó por proteger los derechos de las victimas.

No obstante que en la mesa de negociación se discutió sobre derechos humanos, los mecanismos para que Naciones Unidas verificase su respeto y la independencia del sistema judicial, la reforma de éste como tal no fue tratada. Es más, en este campo se hicieron algunas reformas constitucionales, pero la justicia criminal, es decir, la rendición de cuentas, no fue discutida por los negociadores. Con ello dejaron los derechos de las víctimas desprotegidos; ni siquiera previeron una instancia que se encargara de ellos más adelante. Los negociadores gubernamentales alegaron que la impunidad no era un beneficio exclusivo de la Fuerza Armada y, por lo tanto, propusieron discutirla como parte de la reforma del sistema judicial. Los negociadores del FMLN, por su lado, prestaron poca atención al tema, estaban más interesados en conseguir concesiones relacionadas con la Fuerza Armada que en la reforma del sistema judicial. Es dudoso que el FMLN vislumbrara entonces su trascendencia, quizás porque no contaba con especialistas.

Este vacío es más llamativo porque el desempeño deficiente de jueces y magistrados era evidente, tanto como para que los acuerdos de paz pidieran la depuración del sistema judicial. Esta depuración era y es tan necesaria, que la Corte Suprema de Justicia la comenzó por iniciativa propia, aunque con excesiva lentitud. En 1994, la misión de Naciones Unidas identificó a 48 jueces corruptos y venales. Poco después y a lo largo de tres años, la Corte Suprema de Justicia destituyó a treinta y un jueces, pero sólo uno de ellos por corrupción. Los demás lo fueron por ignorancia inexcusable, incapacidad y negligencia. En la actualidad, casi el 20 por ciento de los jueces de instrucción y la mitad de los de paz no pueden documentar debidamente sus estudios universitarios. Esta situación irregular no se limita a los jueces, sino que comprende a bastantes funcionarios judiciales y abogados. El caso de los jueces es, con todo, más crítico, porque en sus tribunales se inician los procesos y, por lo tanto, tienen facultad para liberar de cargos a los imputados.

Junto a la depuración fue introducida la necesidad de evaluar a los jueces. La primera evaluación, llevada a cabo por el Consejo Nacional de la Judicatura, institución nacida de los acuerdos de paz, encontró oposición tanto en éstos como en la misma Corte Suprema de Justicia, que cuestionaron las cualificaciones de los evaluadores. Cuando las evaluaciones se hicieron públicas, los jueces protestaron porque, según ellos, no se les había dado oportunidad para defenderse. Pese a la resistencia, la evaluación periódica de los jueces ya está aceptada, pero debería ampliarse a los magistrados, a los secretarios y a los auxiliares de los tribunales y, además de considerar la mora procesal, debiera incluir la cualificación profesional de los funcionarios y su preocupación por garantizar los derechos de los procesados y las víctimas. La resisten- 
cia a la evaluación es comprensible, dado que no es costumbre pedir cuentas y mucho menos evaluar conforme a los resultados obtenidos. Sin embargo, estos esfuerzos no han podido evitar que el Consejo Nacional de la Judicatura, la Fiscalía General de la República e incluso el Ministerio de Educación cuestionen las cualificaciones profesionales de los jueces. Su calidad profesional y ética son claves para el buen funcionamiento del sistema judicial.

Aunque las críticas que se puedan hacer a la Corte Suprema de Justicia por su lentitud y renuencia para reconocer la existencia de corrupción en el sistema judicial y expulsar del mismo a los culpables están justificadas, la depuración debe guardar un equilibrio delicado para garantizar simultáneamente la independencia de los jueces. De hecho, éstos, sobre quienes han caído las críticas y la depuración, se sienten vulnerables y, en esa medida, no actúan con la independencia necesaria. A ello contribuye sobremanera que la Corte Suprema de Justicia no cuente con un mecanismo para desechar con rapidez aquellas acusaciones sin mérito, cuyo único propósito es revertir fallos desfavorables. Pero el problema tiene una raíz más honda: la dependencia de los jueces de los magistrados de la Corte Suprema de Justicia. Mientras ésta sea responsable de la disciplina judicial, los nombramientos y las destituciones, los jueces siempre se encontrarán en una posición difícil. En

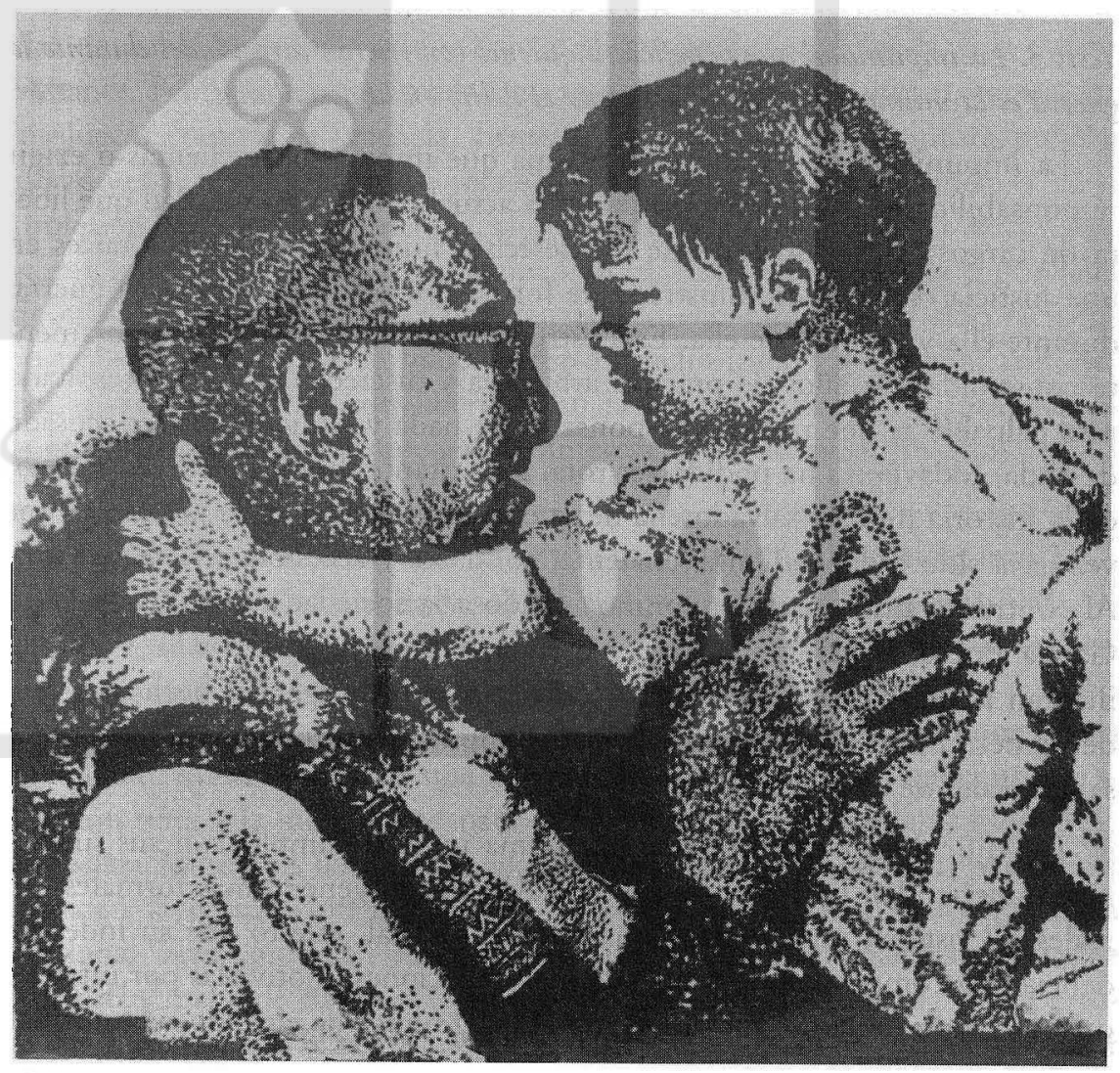


las negociaciones de los acuerdos de paz, Naciones Unidas intentó despojar a este organismo y en particular a su presidente del poder administrativo sobre el sistema judicial, pero el gobierno se opuso de forma tajante. Trasladar esta función al Consejo Nacional de la Judicatura, tal como pretendían los reformadores internacionales, significaba la pérdida de un poder clave para controlar el sistema judicial.

Respetar la autonomía corporativa de los jueces, garantizada por la Constitución, complica aún más la depuración y la institucionalización de un mecanismo que haga efectiva y rápida la rendición de cuentas. Con frecuencia, los jueces salen en defensa de un colega cuestionado, reaccionando en bloque $y$, a veces, sin contar con información de primera mano o a partir de consideraciones ajenas al proceso o al fallo impugnado. Por lo tanto, el desafío planteado consiste en contar con un mecanismo eficaz para expulsar del sistema a los funcionarios judiciales corruptos, arbitrarios e ignorantes, pero salvaguardando al mismo tiempo su independencia. Hay que ir, pues, más allá de la disciplina, del nombramiento y de la destitución e incluir la transparencia del proceso judicial, la formación permanente del funcionario, la obligación del juez de justificar de forma razonada sus decisiones, el proporcionar información a la opinión pública y la aceptación de la crítica.

Tesis 3. La impunidad que beneficia a quienes cometieron atrocidades durante la guerra es la misma que impide perseguir el delito en la actualidad.

La impunidad del pasado es la misma que impide pedir cuentas o exigir responsabilidades a los delincuentes en la actualidad. La impunidad que libera de cargos a los violadores de los derechos humanos hunde sus raíces en una justicia criminal administrada de forma discrecional antes de la guerra, durante ella y después de ella. Esta estructura de impunidad, cuidadosamente construida por años de práctica arbitraria y discrecional y cuyo resultado más palpable es que nadie es responsable de nada y nadie puede ser acusado de nada, todavía no ha podido ser rota. Es bastante difícil encontrar indicios en la historia judicial salvadoreña de que la administración de justicia alguna vez haya sido independiente, eficiente, confiable y accesible a la ciudadanía. Al contrario, casos que han conmocionado a la sociedad como los de Veliz, García Prieto, Vilanova, Saravia, Miranda, Grimaldi, FEDEFUT y jesuitas ilustran la incapacidad del sistema judicial para investigar los hechos, defender el derecho de las víctimas y el de los imputados y condenar a los responsables reales de tales hechos.

Las dificultades que impiden al sistema judicial cumplir con sus funciones, transcienden las reformas superficiales, por lo general más formales que reales. El sistema mismo exige una reforma radical, puesto que su independencia está comprometida y sujeta a manipulaciones, motivadas por intereses diversos. Esto es así porque el sistema judicial nunca ha ejercido su autoridad 
sobre el sector dominante de la sociedad con independencia. Sus problemas son, pues, bastante anteriores a la guérra y causa de ella. La violencia sistemática y general del conflicto armado sólo enfatizó la impotencia judicial. Era inconcebible que investigara a los militares responsables de violaciones de los derechos humanos - ni de ningún otro delito. Y aunque lo hubiera hecho, sus cuerpos auxiliares - los llamados cuerpos de seguridad- no tenían como misión investigar el crimen. Sus acciones así como también las de la Fiscalía General de la República estaban determinadas —y lo siguen estando, en este último caso- por criterios políticos. Nunca hizo esfuerzo alguno para acusar a los altos funcionarios que habían violado la ley. No se molestó en hacer una investigación básica, ni en reunir y garantizar la evidencia forense, ni en interrogar a los testigos con seriedad. La evidencia era ocultada, falsificada y destruida. Le presentaban testigos que cometían perjuro en sus declaraciones sin que les reclamara. Estas son las mismas autoridades que nunca se cansaron de prometer investigaciones exhaustivas cada vez que se cometía un crimen. Esto fue, precisamente, lo que llevó a Mons. Romero a denunciar la parcialidad de una justicia que se ensañaba con el pobre y dejaba impune al poderoso.

Los jueces rara vez cuestionaron el uso de la tortura y nunca se preocuparon por investigarla, aun cuando el imputado les era presentado con evidencias de haber sido maltratado. En aquel entonces, conservar la vida ya era bastante. Peor aún, esta pasividad no respondía tanto a la incompetencia de los jueces como a la creencia, firmemente arraigada en la cultura judicial salvadoreña, de que el único método eficaz para conseguir evidencia es la confesión extrajudicial, obtenida, si es necesario, por coacción. Es cierto que, ya sea por influencia de la tradición judicial, por incompetencia o por falta de independencia, al sistema judicial salvadoreño nunca le ha sido fácil investigar el crimen, pero tampoco mostró mucho interés por contar con esta posibilidad y ejercerla con libertad. En la práctica, estaba organizado para investigar sólo aquellos crímenes que interesasen al orden establecido.

La impunidad del pasado es la misma que impide pedir cuentas o exigir responsabilidades a los delincuentes en la actualidad.

Estas prácticas, lamentablemente, no son cosa del pasado; aunque, en la actualidad, no se realizan de una manera tan descarada. La ausencia de investigación seria y la incapacidad para recoger y proteger la evidencia forense y la declaración de los testigos son algunas de las prácticas que aún persisten e impiden la persecución del crimen. Pero eso no es todo, tanto la Policía Nacional Civil como la Fiscalía General de la República practican el fraude procesal. Prueba de ello es la destitución de más de algún policía y la apertura de varios procesos por este delito. Sin embargo, los jefes policiales que 
ordenaron destruir o fabricar evidencia no han sido investigados. En todos los casos mencionados en la tesis anterior, tanto en el de los jesuitas que, en teoría, pertenecería al pasado, como en los demás, que pertenecerían a la transición, existen indicios fuertes de estas prácticas. Justamente, lo que ha impedido la acusación o la condena de los responsables ha sido la ausencia de investigación policial y judicial. La eficacia de estas prácricas queda demostrada al no haber sido posible sentar ante el juez a ninguno de los autores intelectuales de estos crímenes.

La Comisión de la Verdad se llevó la sorpresa de su vida cuando descubrió que el gobierno no había investigado los actos terroristas y los crímenes atribuidos al FMLN. Esto significa que la actitud de no investigar es superior a la voluntad política. La sociedad salvadoreña no está acostumbrada a exigir cuentas y cuando lo hace, no fundamenta su reclamo en evidencia objetiva. El interés por establecer la verdad de lo sucedido y por identificar a sus autores intelectuales es nulo en la práctica. La transición no ha contribuido a avanzar en este punto. Todavía hoy, la investigación sigue limitada a los primeros pasos: levantamiento de un acta de inspección, denuncia de la parte ofendida y, en algunas ocasiones, declaración de testigos que, por lo general, es irrelevante. En el mejor de los casos, llega hasta los autores materiales y ahí se detiene. Es el mismo patrón que, en el pasado, garantizó la impunidad a los militares, los cuerpos de seguridad, los funcionarios públicos y los poderosos, y que, en la actualidad, explica las investigaciones perversas que concluyen sin encontrar a los verdaderos responsables. La perversidad de la acción policial y del ministerio público no se limita a abortar la investigación, sino que convierte a la víctima o a sus parientes en víctima del imputado y al testigo en candidato a enfrentar una demanda judicial por atentar contra la fama de aquél -cuando no es amenazado y amedrentado para que desista de su testimonio. Esto explica, en parte, que la cantidad de delitos denunciada sea relativamente muy poca -el 35 por ciento, siendo los delitos más graves los más denunciados-, que la cantidad de hechos investigada sea todavía menor y que el número de delitos esclarecidos sea todavía más reducido. Quienes no denuncian creen que es inútil acudir a la policía, alegan no tener pruebas, dicen sentir miedo o juzgan que la ofensa es insignificante.

Esta realidad se intenta ocultar atribuyendo la nulidad de la justicia criminal a los códigos penales vigentes. En consecuencia, algunos sectores de la derecha, encabezados por las autoridades de seguridad pública, exigen endurecer dicha legislación. Pero por ello entienden suprimir los pocos derechos individuales del imputado, mientras que, por otro lado, pretenden conceder al Estado una libertad amplia para capturar y procesar a quienes considere sospechosos. Este sector sostiene que el respeto de las garantías individuales y el sometimiento de la autoridad a la ley impiden desarrollar un combate eficaz contra el crimen. Aparte de ocultar las graves deficiencias existentes en la justicia criminal salvadoreña, esta postura desconoce la experiencia recien- 
te. En efecto, atendiendo a repetidos reclamos, la Asamblea Legislativa ya ha reformado los códigos penales en el sentido exigido por este sector descontento sin que, hasta la fecha, se hayan producido los resultados esperados. Insistir en lo mismo es, en consecuencia, insistir en el mismo error y en el engaño, con lo cual los únicos que obtienen ventajas son los criminales.

Más importante que reformar la legislación para endurecerla, recortando las garantías individuales y abriendo la mano a la poderosa y con frecuencia arbitraria acción estatal, hubiera sido aprender de la metodología de la Comisión de la Verdad y de los asesores extranjeros que ayudaron a echar a andar la Policía Nacional Civil. Pero éstos se encontraron con una oposición tan cerrada, precisamente, en aquellos que más necesitaban de formación y experiencia, que su paso por El Salvador fue desaprovechado. La exhumación de las víctimas de El Mozote, donde la evidencia forense y el testimonio establecieron sin lugar a duda la responsabilidad de la Fuerza Armada, ilustra una de esas oportunidades que fue desaprovechada. Un sector importante de la sociedad salvadoreña se resiste, incluso hoy en día, a aceptar las conclusiones de esta investigación, no obstante la evidencia. Esta actitud sólo puede ser calificada como obstinación. En este sentido, uno de los reclamos que puede hacerse a la Comisión de la Verdad es no haberse preocupado por demostrar cómo la investigación adecuada puede determinar con bastante acierto la responsabilidad de un crimen.

La ausencia de investigación seria y la incapacidad para recoger

y proteger la evidencia forense y la declaración de los testigos son algunas de las prácticas que aún persisten e impiden la

persecución del crimen. Pero eso no es todo, tanto

la Policía Nacional Civil como la Fiscalía General de la República practican el fraude procesal.

Tesis 4. El gobierno de Estados Unidos, por intereses ajenos a El Salvador, ha contribuido y contribuye a la impunidad.

El gobierno de Estados Unidos, a través de su Departamento de Justicia, invirtió muchos millones de colones en dos proyectos, cuyo propósito era dotar a El Salvador de los instrumentos indispensables para la investigación policial y de una legislación penal actualizada. Pese a los millones invertidos, ninguno de los dos proyectos consiguió su objetivo, sino que, además, los dos contribuyeron a la impunidad.

A partir de 1985, el "Programa internacional para el adiestramiento y la investigación criminal" asesoró a los cuerpos de seguridad salvadoreños en las 
técnicas de investigación criminal y de manera especial a la llamada Comisión de Investigación de Hechos Delictivos, presentada como el instrumento idóneo para llenar el vacío en la investigación criminal, y a la Unidad Ejecutiva Antinarcotráfico. Diez años después, estaba demostrado que ninguna de las dos unidades había hecho una investigación que concluyera en la captura de los autores intelectuales de un crimen, ni que la dedicada a combatir el tráfico de drogas hubiese interceptado, excepto en dos ocasiones, un cargamento importante de estupefacientes o armas. Ninguna de las dos unidades contribuyó al desmantelamiento del crimen organizado, ni investigó asesinatos con aparente motivación política, ni identificó el origen de las muchas amenazas de muerte, que proliferaron después de 1992 y de las cuales fueron víctimas varias personalidades de la oposición política, así como también dirigentes sociales y religiosos y diplomáticos. Al contrario, había indicios de que la Comisión de Investigación de Hechos Delictivos servía más para encubrir a los autores de estos crímenes - algunos de los cuales formaban parte de la misma unidad-, tal como sucedió en el caso de los jesuitas, que para esclarecerlos.

En 1994, la misión de Naciones Unidas reconoció que era evidente que el Estado salvadoreño no cumplía con una de sus responsabilidades más graves, la de garantizar los derechos fundamentales, al no respetar las normas básicas de la investigación criminal y violar las del debido proceso. En ese entonces, la misión consideró que la impunidad tolerada y promovida por el Estado era la amenaza principal para el derecho a la vida. Pero Estados Unidos apostó por esa estructura aun cuando hacía posible la impunidad y con la cual los funcionarios de su gobierno se sentían muy cómodos. De esta manera, además de perder tiempo y dinero, impidió el desarrollo de nuevas estructuras que, si hubieran contado con el respaldo adecuado, hubieran podido marcar el inicio de una nueva era en la historia de la justicia criminal de El Salvador. Este fue el caso del Departamento de Investigación contra el Crimen Organizado, una entidad establecida por recomendación del llamado Grupo Conjunto - creado en 1993 para investigar lo que la Comisión de Investigación de Hechos Delictivos y la Unidad Antinacotráfico no investigaban- para continuar las averiguaciones sobre las actividades de organizaciones armadas, dedicadas al crimen político y común. Después de superar muchas dificultades de todo tipo, la nueva unidad obtuvo éxitos notables: descubrió al grupo conocido como "La sombra negra", una organización armada, dedicada a la limpieza social, de la cual formaban parte presuntamente, hasta donde se pudo averiguar, el gobernador del departamento de San Miguel, el alcalde y la máxima autoridad de la Policía Nacional Civil de la ciudad de San Miguel y otros agentes provenientes de la antigua Policía Nacional, y avanzó mucho en las investigaciones de los asesinatos de Veliz, García Prieto y Franco. Estos éxitos eran la mejor muestra de la incapacidad de las dos unidades patrocinadas por Estados Unidos y del equívoco apoyo 


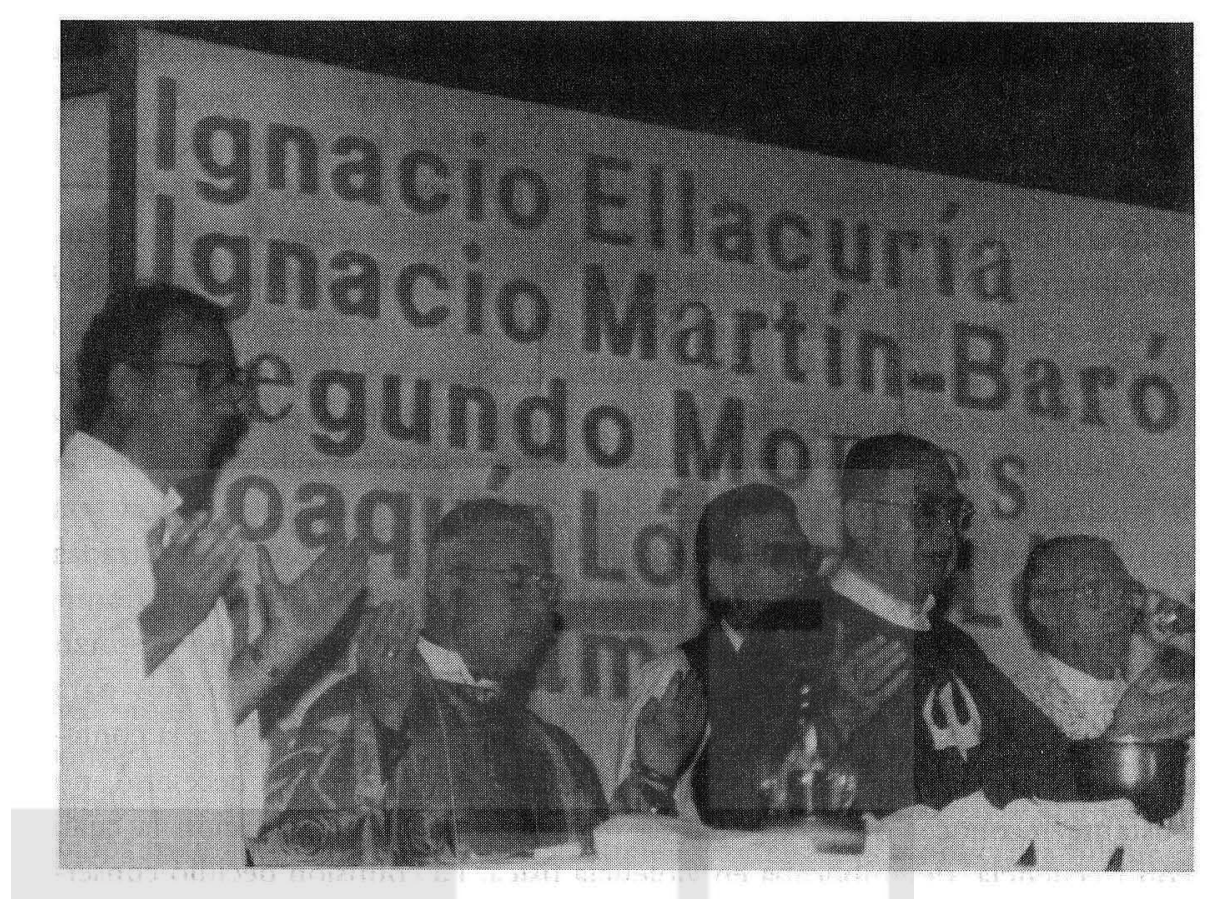

logístico y financiero prestado por el gobierno de dicho país. Contradicroriamente, poco después, las actividades del Departamento de Investigación contra el Crimen Organizado fueron suspendidas y éste quedó relegado al olvido.

A pesar de la evidencia, Estados Unidos nunca admirió que la Comisión de Investigación de Hechos Delictivos no aportaba ninguna solución, sino que más bien era el problema, y no sólo por omisión, sino por la participación de sus miembros en las redes del crimen organizado. El experto independiente de Naciones Unidas la consideró una de las causas principales de la ausencia de resultados positivos en la investigación criminal y la Comisión de la Verdad asegura que dicha comisión encubrió violaciones de los derechos humanos. Pero el Departamento de Justicia estadounidense no podía reconocer su fracaso cuando la ayuda de Washington a El Salvador estaba siendo cuestionada en el Congreso. Contradiciendo toda la evidencia disponible, el Departamento de Justicia reconoció a la Comisión de Investigación de Hechos Delicrivos como un cuerpo competente de investigación criminal y presionó para que, junto con la unidad creada para luchar contra el narcotráfico, fuera integrada en la Policía Nacional Civil, previo acuerdo secreto con el FMLN. Este aceptó la incorporación a cambio de no retrasar la baja de los oficiales militares depurados por la comisión establecida para tal efecto, a lo cual, de hecho, el gobierno de Cristiani estaba obligado por los acuerdos de paz. Una vez integrada en la Policía Nacional Civil, la Comisión de Investigación de Hechos Delictivos conservó su antigua dirección, corrupción, tolerancia frente al delito e ineficacia. 
Estados Unidos decidió intervenir también en la revisión y actualización de la legislación penal salvadoreña, un proyecto en el cual su Agencia Internacional para el Desarrollo invirtió varios millones de colones. La revisión primero estuvo a cargo de asesores estadounidenses, pero sin mucho éxito, porque no comprendieron la mentalidad y la cultura judicial latinoamericanas; luego, éstos fueron reemplazados por los sudamericanos, quienes, pese a contar con las ventajas con las cuales sus antecesores no contaban, encontraron fuerte resistencia al cambio. Después de cinco años de trabajo, la llamada Comisión Revisora de la Legislación Salvadoreña había hecho pocos avances. Aunque contaba con buenos estudios sobre los problemas principales de la justicia criminal, rehusó enfrentarlos y, por consiguiente, las propuestas que finalmente presentó a la Asamblea Legislativa no fueron tan avanzadas como cabría esperar. Aun cuando tenía claridad sobre sus objetivos, la Comisión Revisora fue tímida en sus propuestas. Así, por ejemplo, no se esforzó por suprimir la confesión extrajudicial o por establecer mecanismos para dejar en libertad a los imputados capturados antes del juicio. Vio a la confesión extrajudicial como un elemento cultural y como un mal necesario, no obstante reconocer que era obtenida por medio de la intimidación la cual, con frecuencia, desembocaba en violencia física. La comisión decidió conservarla con el pretexto de que la policía no poseía capacidad científica para investigar el crimen. Como la política exterior estadounidense hacía caso omiso de los derechos humanos, la comisión no prestó atención a reformas que garantizaran su observancia.

Aun cuando las reformas propuestas a la Asamblea Legislativa en 1989 eran superficiales, los diputados introdujeron tales cambios que su propósito original se desvaneció, con lo cual los problemas ya existentes se agravaron. Mientras las Comisión Revisora guardaba silencio ante el rechazo de la Asamblea Legislativa, la Agencia Internacional para el Desarrollo incluyó las reformas en su lista de logros. La comisión pretendía transformar una legislación penal propia de un Estado de excepción en otra que protegiera los derechos individuales de los sospechosos e imputados. Pero los diputados salvadoreños no aceptaron el cambio y prefirieron mantener una legislación más en consonancia con un Estado de excepción. Este es el fondo de la disputa que todavía persiste alrededor de la legislación penal.

La falta de logros en este campo no se debe a deficiencias técnicas, sino a resistencia política y a una cultura autoritaria. El gobierno salvadoreño aceptó los dólares estadounidenses, con los cuales pagó jugosos salarios a los abogados que hicieron los estudios y formularon las propuestas, aun cuando no tenía intención de aceptarlas. Ninguna reforma que significara alterar las relaciones de poder, incluyendo las que rigen al Órgano Judicial, o limitase el espacio para la acción arbitraria del Estado tenía posibilidades de prosperar. Al plegarse al juego del gobierno salvadoreño, de hecho, Estados Unidos, entre 1984 y 1991, intervino para no disminuir el riesgo de la represión 
arbitraria y para conservar la impunidad tradicional de los funcionarios públicos y los criminales influyentes. Esta paradójica postura se explica porque los que impulsaron esta reforma optaron por desconocer el funcionamiento real del sistema judicial salvadoreño y el verdadero interés de sus contrapartes salvadoreñas: conservar el orden establecido intacto. En resumen, Estados Unidos se alió con aquellos sectores indiferentes a las reformas, cuando debió haber sido lo contrario, y así, errores que debieron haber sido analizados con cuidado, fueron disculpados. El caso de los jesuitas ilustra esta actitud irracional e ideologizada de los funcionarios estadounidenses. El embajador Walker defendió al jefe de la Comisión de Investigación de Hechos Delictivos, encargado de investigar la masacre ocurrida en la UCA, aun cuando la evidencia disponible indicaba que sus investigaciones no conducían a ninguna parte.

Cuando no existe voluntad política para introducir las transformaciones necesarias es comprensible concentrarse en la capacitación técnica, pero entonces el éxito de la ayuda externa se reduce a la mera transferencia de habilidades y se olvida de evaluar cómo éstas son puestas en práctica, a partir de los resultados. La mejora de las habilidades judiciales y policiales fue una pantalla para ocultar la ausencia de cambios más fundamentales en la justicia criminal salvadoreña. En repetidas ocasiones, los expertos del $F B I$ alabaron la capacidad técnica de la Comisión de Investigación de Hechos Delictivos para tomar huellas dactilares y balísticas, pero ignoraron la incapacidad para utilizarlas en las averiguaciones de atrocidades y crímenes cometidas durante y después de la guerra. Hasta ahora, nadie ha sido condenado a partir de evidencia obtenida con estos medios científicos. Esta experiencia es un buen ejemplo de los riesgos inherentes a decisiones tomadas sólo atendiendo a criterios políticos. Sin embargo, Estados Unidos no parece haber aprendido la lección, porque está cometiendo el mismo error con la asistencia que presta en la actualidad a la Policía Nacional Civil. Nada más que ahora ya no se trata de un plan contrainsurgente, sino contra el narcotráfico. Con este pretexto, los asesores estadounidenses han recuperado el control sobre la policía, pero de nuevo han prescindido del entorno social, han desconocido la agenda gubernamental y subestiman la resistencia al cambio.

Tesis 5. Aunque la Comisión de la Verdad proporcionó verdad en alguna medida, el gobierno de Cristiani eliminó de un plumazo la posibilidad de hacer justicia, no obstante su preocupación por el Estado de derecho.

Las partes acordaron que el informe de la Comisión de la Verdad daría pie para continuar sus investigaciones y abrir procesos judiciales en aquellos casos donde hubiese mérito para ello. Sin embargo, al constatar que la averiguación de los comisionados había arrojado resultados concretos, incluidos los nombres de algunos de los responsables principales de algunos crímenes, el gobierno se echó para atrás y, en complicidad con los partidos políticos, 
aprobó la ley de amnistía, cerrando así la puerta para que el sistema judicial retomara el informe y contribuyera a esclarecer la verdad y buscara la justicia.

Esta comisión era necesaria en El Salvador, porque su sistema judicial no era ni independiente, ni creíble. De esta manera, la transición brindó una oportunidad para llevar a cabo algunas investigaciones creíbles e independientes que, a su véz, demostraran a la sociedad salvadoreña que ello es posible. La Comisión de la Verdad demostró cómo se puede investigar el crimen y recolectar evidencia para sustentar los cargos. Sus investigadores, por ser ajenos al conflicto, se ganaron la confianza de muchos testigos, quienes les proporcionaron la información necesaria para reconstruir los hechos e identificar a los responsables. Su interés en conocer la verdad los llevó a buscar a los sobrevivientes para escuchar su versión de los hechos, sin esperar a que éstos se presentaran en sus oficinas. Su independencia les permitió una libertad pocas veces vista en El Salvador. Sólo así se explica que hayan atribuido responsabilidad por violaciones graves de los derechos humanos al Estado y a sus funcionarios y, correspondientemente, el rechazo de sus resultados y la resistencia a aceptar sus consecuencias. La experiencia del equipo fue muy valiosa para analizar la información y aplicar las normas reconocidas por la comunidad internacional —indispensables para la reconstrucción de los hechos. Expertos en antropología forense ayudaron a exhumar los restos humanos de algunas masacres, a identificar a las víctimas y a determinar las causas de su muerte. Desde este punto de vista de la evidencia y del debido proceso, los investigadores de la Comisión de la Verdad contaron con unos recursos novedosos y sus resultados fueron también tan novedosos que un sector social importante, aun hoy en día, se niega a aceptarlos.

Este trabajo, sin embargo, de ninguna manera puede sustituir al procedimiento judicial. Una comisión de la verdad no es una instancia judicial, ni libera al Estado de su obligación de investigar las violaciones de los derechos humanos para garantizar que la verdad sea conocida, que el proceso judicial se desarrolle normalmente y que los culpables sean sancionados, conforme a la ley. La actitud salvadoreña ante la Comisión de la Verdad se mueve entre estos dos extremos: por un lado, juzga que la verdad conocida por su informe es suficiente como para no seguir las investigaciones, pero, por el otro lado, ha "olvidado" el informe y su verdad, considerándose libre de toda obligación o responsabilidad al respecto. El argumento del gobierno de Cristiani que acusó a la Comisión de la Verdad de haber invadido la jurisdicción del Órgano Judicial tendría visos de autenticidad si no hubiera promovido de inmediato la amnistía total, incluyendo a sus propios funcionarios, y si, en vez de ello, hubiera creado un mecanismo eficaz y confiable para ventilar las acusaciones en los tribunales. La amplitud y la naturaleza de la violencia de los años de guerra exigen una justicia ejemplar de acuerdo a la ley y al principio, establecido en la legislación internacional e incluso en la Constitución salvadoreña, que sostiene que ciertas conductas nunca son permisibles. 
La participación extranjera en el esclarecimiento de la verdad salvadoreña, aun siendo parcial, por incompleto, demostró el interés de la comunidad internacional, su ausencia de temor para identificar a los responsables de algunos de los crímenes más relevantes y la importancia de la legislación internacional sobre el tema. Si este significado de la Comisión de la Verdad fue pasado por alto, los juicios contra varios altos oficiales salvadoreños en Francia y Estados Unidos, y la posibilidad, aun remota, de investigar a los autores intelectuales de la masacre de la UCA han hecho evidente que es posible perseguir a los violadores de los derechos humanos, pese a la amnistía general vigente en El Salvador. Si el derecho a la justicia es negado en el propio país, cada vez hay más posibilidades para reclamarlo fuera. La presión internacional ha probado ser decisiva para conseguir que un determinado país confronte los abusos del pasado. Este es el caso de Chile, cuya sociedad se había negado a llevar a Pinochet a los tribunales hasta que la presión internacional lo hizo inevitable. Un proceso parecido está teniendo lugar también en Argentina. Sin embargo, la postura de la comunidad internacional ante amnistías amplias, como la salvadoreña, no posee aún la consistencia y la firmeza exigidas por la justicia.

Así como la comunidad internacional no puede reemplazar la labor del sistema judicial local, tampoco puede sustituir el proceso social por el cual las atrocidades del pasado son asumidas. Por su propia naturaleza, estos procesos suelen ser dolorosos y no exentos de turbulencias, pero son igualmente necesarios. Los procesos en los tribunales extranjeros, aunque atraen mucha prensa y tal vez consiguen relevancia política, contribuyen poco a impulsar estos procesos nacionales tan necesarios ahí donde tuvo lugar la violencia, precisamente, porque su influencia es limitada. En cambio, un proceso judicial local, sólo por su ubicación, ya es parte de ese proceso social para asumir el pasado. Por eso, la UCA insiste en agotar todas las instancias previstas por la ley para reclamar justicia. Es más vistoso acudir a un tribunal extranjero, pero para la sociedad salvadoreña es más saludable confrontarse a sí misma con su propio pasado en El Salvador.

Las partes acordaron que el informe de la Comisión de la Verdad daría pie para continuar sus investigaciones [...] al constatar que la averiguación de los comisionados había arrojado resultados concretos, incluidos los nombres de algunos de los responsables principales de algunos crímenes, el gobierno se echó para atrás y, en complicidad con los partidos políticos, aprobó la ley de amnistía, cerrando así la puerta para que el sistema judicial retomara el informe y contribuyera a esclarecer la verdad y buscara la justicia. 
Ahora bien, la comunidad internacional tiene un papel importante en cuanto a animar y presionar, si es necesario, para que ese proceso social tenga lugar y en cuanto a apoyar a las organizaciones no gubernamentales locales dispuestas a impulsarlo. Si algún fallo tuvo la Comisión de la Verdad es no haberse preocupado por transferir sus habilidades y conocimientos de investigación y justicia criminal, es decir, debió haber pensado a largo plazo, de tal manera que la restauración de la dignidad de las víctimas, el reconocimiento de lo sucedido, las reparaciones materiales y morales y los fundamentos para llevar a cabo la reconciliación social hubiesen quedado garantizados de una manera institucional. Esta clase de comisiones no debiera conformarse con dejar un informe sobre violaciones y responsables, sino que también debiera facilitar un proceso social de largo plazo y nunca servir como subterfugio. Es indudable que esto depende, en gran parte, de la disponibilidad del gobierno en cuestión para aceptar sus hallazgos y de la responsabilidad estatal; pero sus integrantes, por lo general extranjeros, no debieran olvidar que una de sus misiones es ayudar a las instituciones estatales a asumir su responsabilidad al mismo tiempo que evitan crear contextos donde la verdad sea ignorada u olvidada. En El Salvador, nada de esto ha sido posible, ni siquiera se adoptaron las sanciones administrativas recomendadas por la Comisión de la Verdad y se permitió que aquellos cuyos nombres aparecen en su informe ocupen cargos públicos e incluso de elección popular.

Tesis 6. Si bien la estructura de impunidad tiene un propósito político claro, su conservación es posible por la anuencia de un sistema judicial venal.

Es innegable que la estructura de impunidad tiene una finalidad política, pero su funcionamiento y conservación están relacionadas con una justicia constitucional deficiente; con una justicia criminal lenta, lo cual, además, agrava el problema de los reos sin condena, cuyo número no baja en la proporción deseada; con la concentración del poder en la presidencia de la Corte Suprema de Justicia, la cual controla el sistema judicial en su totalidad, incluidos los abogados; con una carrera judicial mal planteada y con jueces y magistrados incompetentes y corruptos. No son pocos los jueces y magistrados que carecen de capacidad para analizar y aplicar la legislación relevante, que no están familiarizados con las normas de los derechos humanos, ni con el derecho internacional e incluso con la Constitución salvadoreña. De aquí resulta que las decisiones judiciales con frecuencia adoptan una perspectiva literal y que jueces y magistrados practiquen una especie de formalismo ritual, que los lleva a una conducta burocrática y pasiva, renunciando a asumir la dirección del proceso. Dicho de otra manera, los funcionarios judiciales son piezas de un engranaje autoritario, del cual ni siquiera los abogados están libres — si es que aspiran a continuar en la esfera judicial.

Esta situación no se explica por salarios bajos, ni por escasez de jueces, sino por algo más radical, por la mediocridad de los funcionarios judiciales, 
quienes son formados - cuando su formación es seria - dentro de una larga tradición judicial muy pobre, y por el modelo autoritario, en el cual deben desenvolverse. El nombramiento de jueces, magistrados y representantes del ministerio público no considera la formación, la experiencia y la integridad moral de los candidatos, sino casi sólo el criterio político. Aun cuando el Consejo Nacional de la Judicatura ha introducido criterios de profesionalismo, experiencia e integridad en el nombramiento de los jueces, persiste todavía el compadrazgo. Las ternas son devueltas por la Corte Suprema de Justicia si los magistrados no encuentran en ellas a los candidatos que quieren favorecer. Es así como la Corte Suprema de Justicia continúa ejerciendo una influencia malsana en el sistema judicial. Asimismo, debido a su poder omnímodo, todavía aconseja a los jueces y magistrados sobre cómo llevar ciertos casos o estos últimos buscan su consejo para no poner en peligro su carrera judicial. Este verticalismo proverbial no contribuye en nada a la actuación independiente y creíble. Las amenazas e intimidaciones de los litigantes influyentes todavía determinan el destino de demasiados procesos judiciales.

.. la UCA insiste en agotar todas las instancias previstas por la ley para reclamar justicia. Es más vistoso acudir a un tribunal extranjero, pero para la sociedad salvadoreña es más saludable confrontarse a sí misma con su propio pasado en El Salvador.

Tesis 7. El concepto de que los casos criminales deben ser decididos de acuerdo a la evidencia y no a la influencia política o económica del acusado o la víctima es revolucionario.

La justicia criminal salvadoreña ha sido inadecuada por no decir que, en la práctica, es inexistente. No obstante haber demostrado su ineficacia, se sigue confiando en los métodos del pasado para investigar el crimen. En realidad, no ha habido más que un método, la confesión extrajudicial, con frecuencia extraída por intimidación e incluso por la fuerza. Por lo demás, no existe política para recolectar y preservar la evidencia, a los testigos se les da poca importancia, no gozan de protección alguna y su testimonio es manejado de forma inadecuada, no se cuenta con medios técnicos para establecer la causa, la manera y la hora de la muerte y la presencia y la acción de la Fiscalía General de la República, que tiene el monopolio de la investigación judicial, son lentas y muy deficientes. No es raro que cuando se presenta en el sitio donde se ha cometido un crimen, la evidencia ya ha desaparecido, como en el caso de Katya Miranda, la interceptación y escucha de llamadas telefónicas y algunos secuestros. Esta incapacidad para investigar se refleja luego en los fallos de jueces y magistrados, quienes ante la falta de eviden- 
cia o ante una evidencia débil e incluso inválida, que les facilita dar con el pretexto legal que necesitan, liberan de cargos a los imputados.

Aunque parezca lo contrario, no es fácil dotar al sistema judicial de una buena capacidad para investigar el crimen, porque ahí se juega el control sobre el proceso penal. Primero fueron la Fuerza Armada y Estados Unidos los que se negaron a entregar ese control; en la actualidad, es el poder ejecutivo, a través de la dirección de la Policía Nacional Civil, en cuyas manos se han acumulado la investigación policial, la de inteligencia, a través del Organismo de Inteligencia del Estado - no obstante que la ley no lo autoriza-, y la judicial, por medio del control que ejerce sobre la Fiscalía General de la República -no obstante que la ley dice lo contrario. La situación creada es muy peculiar, la Policía Nacional Civil se resiste a aceptar la dirección de la Fiscalía General de la República en la investigación criminal, pero ésta no ha demostrado poseer ni la independencia ni la capacidad para asumir esta nueva responsabilidad. A ello hay que agregar la formación académica deficiente de los fiscales, su inexperiencia y la ausencia de medios técnicos para un desempeño eficiente. Se cree que siendo abogado se puede ser fiscal sin más. Ante esta confabulación del poder ejecutivo, que, en definitiva, controla la investigación y la acusación judicial, el ciudadano se encuentra inerme.

Modificar este monopolio del poder es una tarea compleja y de largo plazo, que implica transformar los patrones culturales actuales. La sociedad salvadoreña no está acostumbrada a fundamentar la responsabilidad en la evidencia objetiva. De hecho, no está acostumbrada a ninguna evidencia que no sea la confesión del acusado y la creencia popular, la cual se configura de acuerdo a las posiciones ideológicas y suele ser inconsistente con la evidencia disponible. En la práctica, el interés por establecer una verdad objetiva e identificar a los autores intelectuales es poco. Lo normal es que la investigación se limite a los primeros eslabones de la cadena. Se puede objetar, no sin cierta razón, que esto es así por la falta de colaboración de la sociedad y en particular de los testigos. Cabe preguntarse, entonces, por qué los testigos no colaboran con la investigación judicial. La respuesta está en la tradición de no investigar para no reunir evidencia. En ella, el testigo, en lugar de ser un colaborador valioso, es un obstáculo indeseable. Por eso, su testimonio es poco apreciado y no es protegido debidamente, así como su integridad física tampoco goza de la protección adecuada y es víctima de amenazas que con frecuencia lo obligan a abandonar el país. En este esquema, el acusado es presentado como víctima inocente del testigo. Esa fue la experiencia de Lucía Cerna, la primer testigo del caso de los jesuitas, quien dijo haber visto soldados en la residencia de la UCA la noche de la masacre; la de la agente de la Policía Nacional Civil que dio la declaración que permitió identificar a los responsables de "La sombra negra" y del testigo del secuestro y homicidio de un joven, a quien la Fiscalía General ofreció garantías a cambio de su declaración, pero que después no cumplió. El testigo apareció muerto en circunstancias no aclaradas. La Comisión de la 
Verdad encontró testigos muy atemorizados, lo cual, de hecho, fue un obstáculo difícil de salvar para llegar a los hechos y sus responsables.

Tesis 8. El desafio de la investigación criminal consiste en proteger los derechos del sospechoso al mismo tiempo que obtiene evidencia judicial admisible.

La reforma judicial, por la fuerza inercial que poseen los patrones de décadas de impunidad, tiende a reforzar el autoritarismo y a menoscabar los derechos del imputado y de la víctima. Proteger los derechos de ambos, sobre todo del primero, $y$ obrener la evidencia necesaria para comprobar su crimen es la clave de toda investigación judicial. Pero ello requiere de una formación, de una actitud y de unas habilidades muy diferentes a las existentes en la actualidad.

Uno de los obstáculos más grandes que hay que superar para avanzar en esta dirección es desprenderse de la creencia, común por lo demás en América Latina, de que proteger los derechos individuales del sospechoso o imputado equivale a aumentar la tasa de criminalidad y la inseguridad. Esta creencia es propia del modelo autoritario de sociedad y de justicia prevaleciente. Aun siendo contraria a la democracia en la cual se asegura vivimos, se sigue alimentado. Es la cultura autoritaria la que lleva a que la discusión sobre la seguridad ciudadana y el control del crimen se concentre casi de manera exclusiva en la legislación más que en la prevención, el control de las armas de fuego, la formación y el despliegue de la policía y las condiciones sociales y económicas. Obtener condenas a costa de sacrificar los derechos fundamentales de las personas sólo conduce a socavar la democracia. La consolidación democrática requiere asegurar la limpieza procesal de inocentes y culpables y la eficiencia procesal en la aplicación de la ley a los criminales.

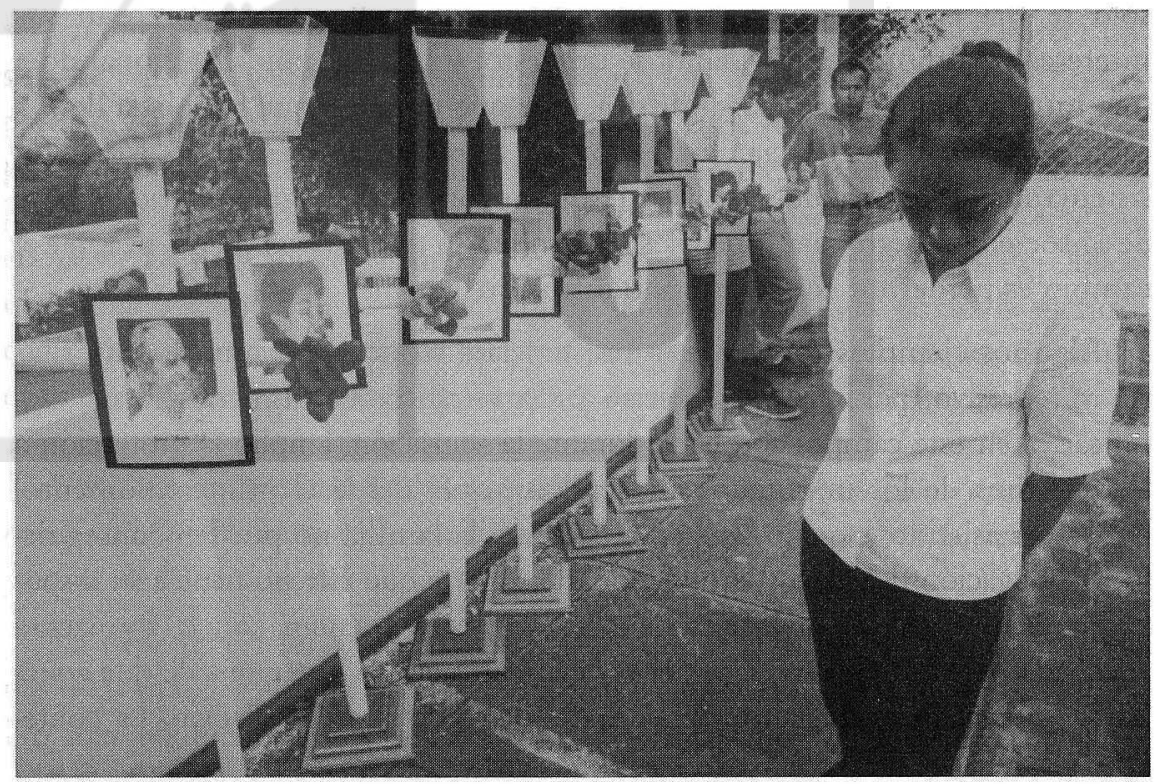


El gobierno de ARENA tiene un concepto todavía más estrecho de lo que debiera ser la reforma judicial. Su preocupación principal es salvaguardar la seguridad jurídica, más que los derechos individuales — que, por otro lado, es un principio básico de la doctrina liberal de todos los tiempos. Pero incluso la seguridad jurídica la entiende en un sentido muy restringido. Para este partido, la necesidad de mejorar el sistema judicial, en cuanto a proporcionarle mayor independencia y eliminar la corrupción, está en función de la inversión extranjera. Su gran preocupación es que ésta no tema la decisión arbitraria de un juez. Lo que el gobierno no puede comprender es que ningún inversionista extranjero puede pensar en serio en colocar parte de su dinero en un país como El Salvador donde, si su inversión compite con la de un ex presidente de la república o alguno de sus socios y surge un conflicto de intereses, el sistema fallará irremisiblemente en su contra. En el otro extremo del espectro político, al FMLN sigue sin preocuparle mucho el destino de la reforma judicial, quizás porque todavía no alcanza a comprender su trascendencia para la democratización y porque está más preocupado por hacer méritos para ocupar cargos públicos.

Las reformas propuestas, y no aprobadas en su totalidad, fueron diseñadas para superar el sistema escrito, cuya naturaleza inquisitorial lo hacía poco apto para contribuir a una transición que quería ser democrática, por otro oral y argumentativo, donde la eficiencia y la transparencia estuvieran mejor garantizadas. Aunque la sustitución de un sistema por otro fue aprobada, de hecho, persisten las prácticas inquisitoriales. El cambio encontró una fuerte resistencia en las instituciones así como también en policías, jueces, fiscales y abogados. La policía todavía alega que las reformas aprobadas entorpecen su trabajo; la empresa privada, que ha tomado muy a pecho los cambios, movida por el impacto negativo de la delincuencia en sus actividades y ganancias, sólo se fija en algunas provisiones concretas, aquellas que más tocan sus intereses patrimoniales, olvidándose del resto; y la población, reaccionando a una intensa campaña propagandística, cree que impiden que la policía lleve a cabo su labor con eficacia. En el fondo, la resistencia responde a que un sistema más abierto y democrático resulta inconcebible para una buena parte de la sociedad, pero para quienes sí entienden lo que está en juego, aceptar el cambio es perder un control importante sobre aquélla.

Algunos ejemplos ilustran esta resistencia a sustituir un modelo autoritario y represivo, por otro más abierto y democrático. La primera reforma significativa en este campo, aprobada durante la transición, amplió la protección a los derechos de los imputados al establecer que, desde el primer momento, deben ser asistidos por un abogado. Si éste o la familia no pueden conseguirlo, es obligación del Estado proporcionarlo. Aparte que éste no tiene a su disposición la cantidad de abogados necesaria, ni éstos cuentan con la formación adecuada para asumir este papel, la Policía Nacional Civil se queja de que aquéllos entorpecen su labor al recomendar al detenido guardar silencio. La confe- 
sión extrajudicial es otro ejemplo de este forcejeo entre el autoritarismo y la democratización. Quienes se oponen a la eliminación de este recurso alegan que la Policía Nacional Civil no tiene capacidad para reunir otro tipo de evidencia. El gobierno y la gran empresa privada son incapaces de comprender que la policía puede obtener resultados satisfactorios si recoge evidencia y si los fiscales interrogan de inmediato a los testigos. El argumento de la derecha está viciado, porque en la medida en que la Policía Nacional Civil pueda continuar apoyándose en la confesión extrajudicial no tendrá motivo para reunir otra clase de evidencia, ni para aprender los métodos científicos comúnmente aceptados. Al final, en lugar de prohibir la confesión extrajudicial, la Asamblea Legislativa aprobó su utilización, pero sólo si está presente el abogado defensor, si aquélla es consistente con la evidencia reunida y si no es obtenida bajo coacción física y, o moral. Aún así, las autoridades de seguridad insisten hasta el día de hoy en la necesidad de suprimir estas restricciones para volver a utilizar la confesión extrajudicial con la libertad del pasado. La detención preventiva fue concebida como una excepción y en su lugar se establecieron algunas alternativas, pero aun antes de la aprobación de los códigos, la propuesta fue alterada en el sentido contrario, la excepción se volvió norma.

La estructura autoritaria tradicional ni siquiera toleró al nuevo código de menores. Con la colaboración de la prensa, las autoridades de seguridad convencieron a la opinión pública de que los menores eran los responsables principales del auge de la delincuencia, cuando en realidad su incidencia era muy limitada, y de lo inadecuado del nuevo código de menores, cuando funciona mucho mejor que la justicia criminal tradicional.

Estos ejemplos muestran que ni los diputados ni las autoridades de seguridad tienen la menor idea de qué sea el derecho individual de la persona y cómo debe ser garantizado y protegido. El propósito de los nuevos códigos era establecer un sistema criminal orientado a asegurar una justicia independiente, rápida, transparente y respetuosa de las garantías y los derechos fundamentales del debido proceso. Buscaban abandonar un sistema escrito e inquisitorial, donde un solo juez investigaba, acusaba, instruía la causa, presidía el plenario y dictaba sentencia por otro más abierto al debate, donde la Fiscalía General de la República tiene una responsabilidad mayor, donde tanto el imputado como la víctima cuentan con espacio para participar y ser escuchados y donde la audiencia pública dificulta los arreglos y las negociaciones de espaldas a la justicia.

Tesis 9. A modo de conclusión: intereses creados de diverso tipo se oponen a la construcción de una institucionalidad que garantice el derecho a la verdad y la justicia de la ciudadania.

La experiencia salvadoreña muestra la dificultad para cambiar las actitudes y las prácticas inveteradas de un sistema judicial tradicional y autoritario. No sólo sus funcionarios deben cambiar de mentalidad y actitud, sino tam- 
bién los políticos y la sociedad. Los asesores internacionales que participaron en las diferentes fases del proceso de reforma no supieron apreciar con precisión esta dificultad. No se trata únicamente de transmitir nuevos conocimientos o habilidades, sino también de transformar una mentalidad y unas actitudes que no conciben otras formas de pensar y encarar la realidad judicial distintas a las propias. El arraigo de esta tradición, el encasillamiento y la falta de perspectiva con facilidad se transforman en intolerancia. Con todo, el proceso por el cual una sociedad cambia sus conceptos y sus prácticas policiales $y$ judiciales aún no es del todo claro. Algunos cambios exigen la formación de una nueva generación de abogados y funcionarios judiciales de acuerdo a la nueva normativa, pero otros son necesarios para garantizar que el proceso de consolidación democrática del sistema continúe, aunque sea lentamente. Los obstáculos para construir un sistema judicial democrático son mayores en países como El Salvador, cuya estructura legal es débil y donde la formación jurídica que se brinda es mediocre. Es equívoco pensar que las transformaciones que tanto se necesitan pueden ocurrir con una o varias reformas al sistema. Más bien se trata de un proyecto de largo alcance.

Además de estas dificultades de carácter cultural y actitudinal, están los intereses creados que son los que, en definitiva, han entorpecido el funcionamiento de la justicia criminal. Tales intereses sólo pueden prosperar si son impunes. Por lo tanto, el sistema judicial ha sido estructurado y conservado, precisamente, para garantizar esa impunidad. Así se explica que ninguna reforma orientada a alterar las relaciones de poder haya sido aceptada. El sistema judicial, tal como existe en la actualidad, es parte integral de una estructura social más autoritaria y vertical que democrática y pluralista y, en consecuencia, ororga los derechos mínimos a los sospechosos o imputados al mismo tiempo que concede un margen amplio a la acción arbitraria del Estado.

Una lección aprendida de la experiencia salvadoreña es que las agendas de las transiciones negociadas deben incluir la reforma del sistema judicial. Aquéllas ofrecen una oportunidad única para impulsar una reforma de por sí compleja y de tanta envergadura. La misión internacional encargada de promover los derechos humanos durante la transición tiene a su alcance una posibilidad única para diagnosticar los males del sistema y proporcionar asistencia técnica para ayudar a superarlas. No obstante, esto nunca podrá sustituir el compromiso del Estado, ni la participación de la sociedad en las reformas. Sería un error considerar los acuerdos de paz como un medio para resolver todos los problemas importantes de un determinado sistema judicial. En el mejor de los casos, éstos establecen las condiciones para permitir su solución en el mediano y largo plazo.

San Salvador, 1 de diciembre de 2000. 